\title{
The future of cardiovascular surgery
}

\author{
Domingo Braile*
}

$\mathrm{B}$

etween March and May, I had the opportunity of participating in three important events with cardiovascular surgeons. The first was the 33rd Congress of the Brazilian Society of Cardiovascular Surgery from March 29 to April 3 in Salvador, Brazil. The second was the 15th Congress of Cardiac Surgery in Mexico and 1st Latin-American Congress of Cardiac Surgery from April 20 thru 22, in the City of Mexico.

The last one was the 86th Annual Meeting of the American Association of Thoracic Surgery from April 29 to May 3, in Philadelphia, United States. On this occasion, as a member of the CTSNet Editorial Counsel, I participated in its ordinary general meeting, in which many subjects of great interest to the BSCVS were discussed. It is important to stress that in recognition of his work, our colleague and friend Dr. José Pedro da Silva was accepted as a full member of the AATS, a position occupied by few surgeons from the USA and only five Brazilians. We congratulate him on his merited achievement.

In these meetings apart from the normal social get together, scientific advances and the utilization of new techniques were presented and widely discussed. Surgeries of aorta diseases were mentioned in all events, with presentations of works performed using classical techniques, but with much emphasis on endovascular procedures, which we should use in the treatment of these severe diseases. During the discussions, there was always a lot of concern related to future perspectives for cardiovascular and thoracic surgeons. On this subject, I must mention the closing speech of the president of AATS, Richard A. Jonas. Born in Australia and with experience in countries including England and China, Dr. Jonas believes that globalization will change the face of cardiovascular surgery over the next two decades. Whether these changes will help or harm us will depend on how we face the challenges that will emerge.

He stressed the importance of adapting training offered in graduation and post-graduation courses to the new realities, to the new methods of spreading knowledge and the developing techniques that will have to incorporate less-invasive procedures and probably the use of robotics at all levels. The aging population (although the focus was on the USA, the same can be said about Brazil), will bring more degenerative cardiovascular diseases to be treated by the cardiovascular surgeon, thus, he must be prepared to treat this important subgroup of society. Finalizing, he emphasized the necessity of cardiovascular surgeons being prepared for the problems of future generations and in particular, in respect to their anxieties. For Dr. Jonas, the important thing is to incorporate the idea that "all benefits of globalization should be equally distributed".

His words are wise and deserve reflection. There is little advantage if a technical-scientific improvement can not be used for the majority of patients. And this question is even more contentious in developing countries such as Brazil, in which the majority of the population does not have financial conditions to pay for highly complex procedures and the government does not adequately remunerate hospitals or physicians. The Brazilian Journal of Cardiovascular Surgery (BJCVS), as a vehicle of scientific knowledge and debate on subjects of interest to the members of the Brazilian Society of Cardiovascular Surgery (BSCVS), offers a space for this discussion and reflection.

In this edition, there is an editorial by Dr. Rui Sequeira de Almeida, member of the Editorial Counsel of the BJCVS, in respect to treatment options for patients with multiple arterial coronary disease. Additionally, we are, with due authorization, reproducing an editorial initially published in the Brazilian Medical Association Journal (JBMA) by Dr. Bruno Caramelli which discusses the compulsory public registration of clinical trials. I recommend these two texts, as they are issues that are of interest to us all.

Our journal is still concerned about becoming indexed to the international databases. Besides 
receiving an increasing number of contributions from colleagues in other countries thanks to the English versions in Scielo (www.scielo.br/bjcvs), in our site (www.rbccv.org.br), and in the link of the CTSnet (www.ctsnet.org/sections/journalsandbooks/journals/ ctjournals.html), as was mentioned in the last edition we are in the Scopus Portal and now in the Copernicus database, too. Even so, we continue fight for indexation in Medline. We up-dated our data in Index Medicus (www.cisi.org), another important well-accepted database that will, for sure, bring greater international acceptance and more articles in the near future.

Another aspect involving the BJCVS that I would like to bring to your attention is the inclusion of young reviewers with the aim of starting their learning process thereby investing in their future. The possible lack of experience will be compensated by their enthusiasm and open mindedness to learn. With the system utilized on the site for the evaluation of works, which allows reviewers access to the reports of other reviewers who are evaluating the same article, everyone will benefit and the journal will, for certain, continuously improve.

We are also considering the adoption of an online system in which, controlled by the Editorial Counsel, readers will be asked about the content of some articles. After reading specific articles, those interested will be able to answer a questionnaire that will be worth points valid in the process of specialization, to become a full member or in the necessity and urgent renewal of the specialization title. Interested members would access the article in the site and quickly and efficiently send their answers by internet. The company responsible for maintaining the site of the RBCCV/BJCVS has this program ready for implementation and now is only waiting for the directorate of the BSCVS. This will increase the interest in both publishing important articles and reading them. All members, from now on, must submit their works for specialization title or to apply for full membership, directly to the site of the RBCCV/BJCVS; just choose when submitting manuscripts for "To submit new article for specialization" or "To submit new article for full membership".

To finish I would like to include some lines referring to the 33rd Congress of the BSCVS. I would like to compliment the organizers, Dr. Ricardo Eloy, Dr. Clotário Cueva and Dr. Waneman de Andrade for the wonderful experience in Salvador that pleased all participants.

Congratulations to our colleagues: Carlos Alberto Mussel Barrozo, Vicente Ávila Neto and Fabio Antonio Gaiotto, whose works received first, second and third places respectively, and will contribute greatly to cardiovascular surgery and to our journal.

To the Directorate led by Dr. Alexandre Visconti Brick (who deservedly received the Zerbini Award for 2005); I wish to convey our recognition for the excellent administration of our Society and I am sure that the good work will continue until 2008 under the new directorate led by Dr. José Teles de Mendonça. The BJCVS will always be prepared to divulge the achievements of our Society that, I am sure, will be many.

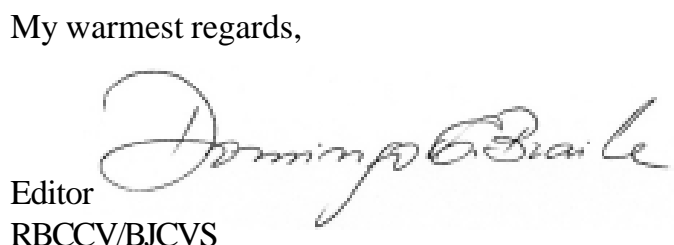

